\title{
AVALIAÇÃO DE NOVAS MATRIZES VÍTREAS PELA TÉCNICA DE TERMOLUMINESCÊNCIA PARA DOSIMETRIA DE DOSES ALTAS
}

\author{
G. S. M. Carvalho*, P. Z. Ferreira*, D. M. Cunha*, N. O. Dantas*, A. C. A. Silva*, A. P. Perini*, \\ L. V. E. Caldas**, B. N. S. Carrera***, S. Watanabe***, L. P. Neves*** \\ *Instituto de Física, Universidade Federal de Uberlândia (INFIS/UFU), Uberlândia/MG, Brasil \\ ** Instituto de Pesquisas Energéticas e Nucleares, Comissão Nacional de Energia \\ Nuclear (IPEN CNEN/SP), São Paulo/SP, Brasil \\ *** Instituto de Física, Universidade de São Paulo (IFUSP), São Paulo/SP, Brasil \\ e-mail: gabrielsmc@ufu.br
}

\begin{abstract}
Resumo: Novas matrizes vítreas foram avaliadas para dosimetria de doses altas. Suas composições nominais $\mathrm{s} \quad \tilde{\mathrm{a}} \quad$ o $20 \mathrm{Li}_{2} \mathrm{CO}_{3} \cdot 10 \mathrm{Al}_{2} \mathrm{O}_{3} \cdot 10 \mathrm{CdO} \cdot 60 \mathrm{~B}_{2} \mathrm{O}_{3}$ $20 \mathrm{Li}_{2} \mathrm{CO}_{3} \cdot 10 \mathrm{Al}_{2} \mathrm{O}_{3} \cdot 15 \mathrm{CdO} .55 \mathrm{~B}_{2} \mathrm{O}_{3}(\mathrm{~mol} \%)$. As matrizes vítreas foram irradiadas com diferentes doses: 50, 100, $200,500,700$ e $900 \mathrm{~Gy}$, e foram analizadas pela técnica de termoluminescência. As curvas de emissão termoluminescente foram obtidas e mostram um grande potencial de uso dessas matrizes para dosimetria de doses altas.
\end{abstract}

Palavras-chave: dosimetria, termoluminescência, matriz vítrea, doses altas, proteção radiológica.

\begin{abstract}
:
New glass matrices were evaluated for high dose dosimetry. Their nominal composition are $20 \mathrm{Li}_{2} \mathrm{CO}_{3} .10 \mathrm{Al}_{2} \mathrm{O}_{3} .10 \mathrm{CdO} .60 \mathrm{~B}_{2} \mathrm{O}_{3}$ and $20 \mathrm{Li}_{2} \mathrm{CO}_{3} .10 \mathrm{Al}_{2} \mathrm{O}_{3} .15 \mathrm{CdO} .55 \mathrm{~B}_{2} \mathrm{O}_{3}$ (mol\%). The glass matrices were irradiated with different doses: 50, 100, 200, 500, 700 and 900 Gy, and analysed via the thermoluminescence technique. The thermoluminescence emission curves obtained showed a great potential of using these matrices in high dose dosimetry.
\end{abstract}

Keywords: dosimetry, termoluminescence, glass matrix, high doses, radiologic protection.

\section{Introdução}

O uso de doses altas de radiação está se tornando um campo com crescimento promissor. Os processos que envolvem doses no intervalo entre 10 Gy e 100 kGy são caracterizados como doses altas e englobam, por exemplo, as atividades de gamagrafia, cura de tintas e vernizes, polimerização de fios e cabos, irradiação de pedras semipreciosas e alimentos, esterilização de materiais cirúrgicos e cosméticos, entre outros [1].

Nestes processos, é necessário a implementação de um controle de qualidade eficiente para assegurar que a dose de radiação correta seja entregue ao objeto em questão. Usualmente, para dosimetria de doses altas, matrizes vítreas são empregadas, e o procedimento de leitura é realizado pela técnica de termoluminescência [2].

Uma grande variedade de matrizes vítreas tem potencial para serem utilizadas como dosímetros de doses altas, pelo baixo custo de produção, por suas propriedades dosimétricas e pelo tamanho relativamente pequeno comparado com outros dosímetros utilizados na área [3].

Matrizes vítreas que contém Cádmio $(\mathrm{Cd})$ em sua composição têm sido avaliadas e mostram resultados promissores para serem utilizadas como dosímetros pela literatura recente [4,5]. Entretanto, mais estudos são necessários para avaliar como a alteração na concentração de Cádmio, na matriz, afeta a sua resposta dosimétrica.

O processo de termoluminescência (TL) é classificado como uma emissão fosforescente termicamente estimulada. Em um isolante ideal, os elétrons ocupam a banda de valência, a banda de condução se encontra inabitada e a separação entre as duas bandas é denominada banda proibida, onde não há níveis de energia para os elétrons ocuparem [6].

Quando o material é irradiado, se a energia do fóton incidente é suficiente para vencer a diferença de energia entre as bandas do material, o elétron irá absorver esta energia e passará a habitar a banda de condução, deixando buracos (vacâncias) na banda de valência.

Se o material possui uma impureza ou dopante, no nosso caso o Cádmio, haverá a inserção de níveis de energia dentro da banda proibida. Esses níveis energéticos atuam como armadilhas de elétrons e buracos, dependendo de sua profundidade na banda. Os elétrons ao tentarem retornar para a banda de valência, serão armadilhados, assim como os buracos, até que algum estímulo, nesse caso térmico, libere eles. Ao aquecer o material, os elétrons recebem energia térmica que se for maior que a profundidade da armadilha, faz com que eles retornem a banda de condução. A partir desse momento, há uma probabilidade de recombinação de elétrons com buracos que depende da temperatura de aquecimento do material. Quando esta recombinação ocorre, há a emissão de um fóton TL. 
À medida que a intensidade da emissão TL pelo material se torna mais intensa, significa que há mais recombinações de elétron-buraco ocorrendo. Conforme se aquece o material, é possível obter uma curva da intensidade da emissão TL em função da temperatura de aquecimento. Esta é denominada a curva de emissão TL [7].

\section{Materiais e métodos}

As matrizes vítreas foram sintetizadas pelo método de fusão em forno de carbeto de silício a $1350^{\circ} \mathrm{C}$ por 15 minutos sob atmosfera de carbono. $\mathrm{O}$ resfriamento foi realizado entre duas chapas de bronze-latão a $0^{\circ} \mathrm{C}$, e tratadas termicamente a $350^{\circ} \mathrm{C}$ por 12 horas.

Foram desenvolvidas amostras de matrizes vítreas $\mathrm{d} \mathrm{e} \quad \mathrm{compos}$ c ção n o m in a 1 $20 \mathrm{Li}_{2} \mathrm{CO}_{3} .10 \mathrm{Al}_{2} \mathrm{O}_{3} .10 \mathrm{CdO} .60 \mathrm{~B}_{2} \mathrm{O}_{3}$ e $20 \mathrm{Li}_{2} \mathrm{CO}_{3} .10 \mathrm{Al}_{2} \mathrm{O}_{3} .15 \mathrm{CdO} .55 \mathrm{~B}_{2} \mathrm{O}_{3}(\mathrm{~mol} \%)$.

As irradiações foram realizadas em um equipamento Gamma Cell-220 que emprega uma fonte de Cobalto60 , com uma taxa de dose de 1,38 kGy/h. As amostras foram posicionadas a uma distância de $10 \mathrm{~cm}$ da fonte e foram irradiadas com as doses: 50, 100, 200, 500, 700 e 900 Gy. Este irradiador está localizado no Centro de Tecnologia das Radiações, do Instituto de Pesquisas Energéticas e Nucleares (IPEN/CNEN-SP), à temperatura ambiente. Para garantir o equilíbrio eletrônico durante as irradiações, as amostras foram cobertas com uma camada de $3 \mathrm{~cm}$ de polimetilmetacrilato (PMMA).

Após as exposições, as curvas de emissão TL foram obtidas em uma leitora Harshaw TLD Modelo 4500, com um computador pessoal para a aquisição de dados. As medições foram realizadas da temperatura ambiente até $400^{\circ} \mathrm{C}$, utilizando um fluxo constante de $\mathrm{N}_{2}$ de $2,5 \mathrm{~L} / \mathrm{min}$ e uma taxa de aquecimento de $10^{\circ} \mathrm{C} / \mathrm{min}$.

\section{Resultados}

A primeira matriz vítrea analisada é a de composição nominal $20 \mathrm{Li}_{2} \mathrm{CO}_{3} \cdot 10 \mathrm{Al}_{2} \mathrm{O}_{3} \cdot 10 \mathrm{CdO} \cdot 60 \mathrm{~B}_{2} \mathrm{O}_{3}$ (mol\%). A Figura 1 mostra as curvas de emissão TL desta matriz para todos os valores de dose irradiada.

A Figura 2 mostra as curvas de emissão TL da segunda matriz vítrea analisada, de composição nominal $20 \mathrm{Li}_{2} \mathrm{CO}_{3} .10 \mathrm{Al}_{2} \mathrm{O}_{3} .15 \mathrm{CdO} .55 \mathrm{~B}_{2} \mathrm{O}_{3}(\mathrm{~mol} \%)$, para todos os valores de dose irradiada.

\section{Discussão}

A matriz vítrea com [10CdO] apresenta um pico com alta intensidade em $160^{\circ} \mathrm{C}$ apenas para a dose irradiada de 900 Gy. Para as demais doses, os picos de emissão TL encontram-se deslocados para temperaturas mais altas, porém possuem intensidade muito baixa de emissão e algumas se sobrepõem (100, 200 e 500 Gy), indicando saturação do sinal. Já na matriz com [15CdO] observa-se picos com alta intensidade de emissão TL a partir da dose irradiada de 200 Gy. Também é possível notar que há um aumento no sinal TL conforme aumenta-se a dose irradiada, com os picos de emissão centrados acima de $200^{\circ} \mathrm{C}$. Por último, ocorre uma saturação do sinal TL na curva de 900 Gy.

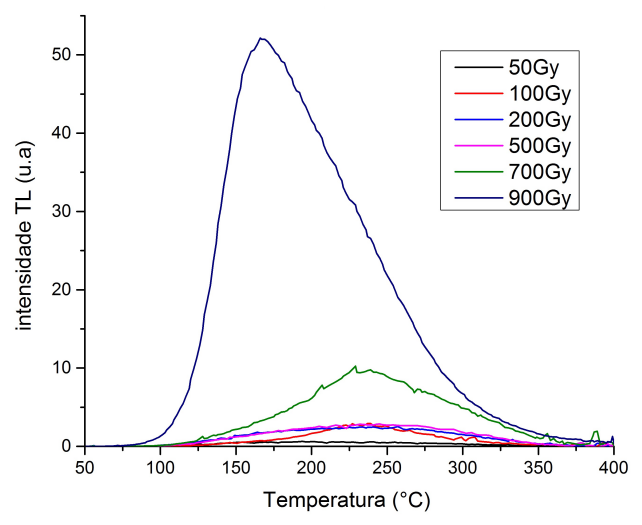

Figura 1: Curvas de emissão TL da matriz vítrea de composição nominal $20 \mathrm{Li}_{2} \mathrm{CO}_{3} \cdot 10 \mathrm{Al}_{2} \mathrm{O}_{3} \cdot 10 \mathrm{CdO} .60 \mathrm{~B}_{2} \mathrm{O}_{3}$ (mol\%) para doses altas de radiação.

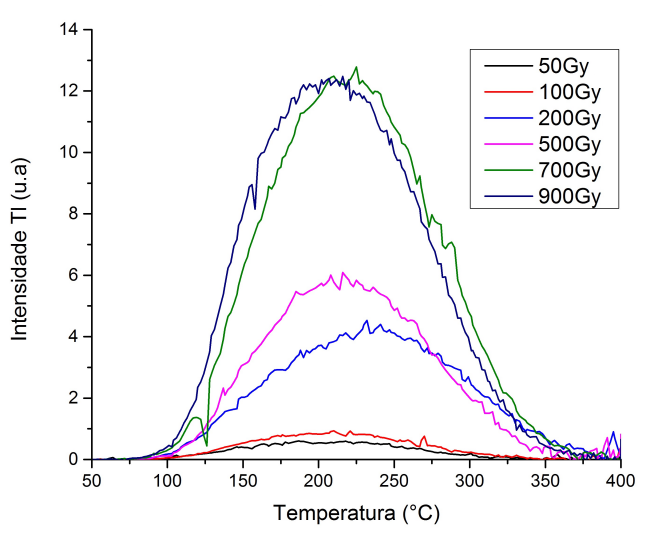

Figura 2: Curvas de emissão TL da matriz vítrea de composição nominal $20 \mathrm{Li}_{2} \mathrm{CO}_{3} \cdot 10 \mathrm{Al}_{2} \mathrm{O}_{3} .15 \mathrm{CdO} .55 \mathrm{~B}_{2} \mathrm{O}_{3}$ (mol\%) para doses altas de radiação.

\section{Conclusão}

Foi observado que a matriz vítrea com maior concentração de Cádmio (15CdO) possui uma resposta que pode ser melhor tratada por métodos quantitativos 
para todos os valores de doses comparando com a matriz de menor concentração de Cádmio (10CdO). A matriz de $[15 \mathrm{CdO}]$ também apresentou picos de emissão acima de $150^{\circ} \mathrm{C}$, evitando que fatores ambientais como temperatura ambiente, umidade do ar e radiação de fundo, possam exercer influência considerável na curva de emissão TL. Vários outros testes são necessários para prosseguir com a caracterização completa das propriedades dosímetricas dessas matrizes, como: curva de dose-resposta, desvanecimento e reprodutibilidade da resposta, dependências angular e energética e dose mínima detectável.

\section{Agradecimentos}

Este trabalho recebeu apoio financeiro das seguintes agências: Fundação de Amparo à Pesquisa do Estado de Minas Gerais (FAPEMIG, Projeto $n^{0}$. APQ-02934-15), CAPES (Projeto Pro-Estratégia no. 1999/2012), CNPq (Projeto no. 119483/2015-7) e INCT (Projeto INCT Metrologia das Radiações em Medicina).

\section{Referências}

[1] Okuno E, Yoshimura E. Física das Radiações. Oficina de Textos: São Paulo; 2010.

[2] McLaughlin WL, Boyd AW, Chadwick KH, McDonald JC, Miller A. Dosimetry for radiation processing. Taylor and Francis: London; 1989.

[3] Teixeira MI. Propriedades dosimétricas de vidros comerciais e de areia para doses altas [dissertação]. São Paulo: Universidade de São Paulo; 2004.

[4] Manohara BM, Nagabhushana H, Thyagarajan K, Daruka Prasad B, Prashantha SC, Sharma SC, Nagabhushana BM. Cadmium silicate nanopowders for radiation dosimetry applications: luminescence and dielectric studies. Journal of Asian Ceramic Societies. 2015; 3(2):188-197.

[5] Anjaiah J, Laxmikanth C, Kistaiah P, Veeraiah N. Dosimetric and kinetic parameters of lithium cadmium borate glasses doped with rare earth ions. Journal of Radiation Research and Applied Sciences. 2014; 7(4): 519-525.

[6] McKeever SWS, Moscovitch M, Townsend PD. Thermoluminescence dosimetry materials: properties and uses. Nuclear Technology Publishing: England; 1995.

[7] McKeever SWS. Thermoluminescence of solids. Cambridge University Press; 1988. 